\title{
THE IMPENETRABLE COMMUNITY OF PRACTICE: THE LIVED EXPERIENCE OF STUDENT NURSES AND THEIR ICT USE IN CLINICAL PRACTICE
}

\author{
Lyndsey McPhail', Dawne Gurbutt ${ }^{2}$ \\ ${ }^{1}$ University of Central Lancashire (UK) \\ ${ }^{2}$ University of Central Lancashire (UK)
}

\begin{abstract}
In recent years the use of Information, Communication and Technology (ICT) has transformed the delivery of healthcare within nursing practice. Research evidence and policy reviews suggest that the difficulty that some mature, female student nurses experience in the use of ICT in practice impacts their professional development. It could be argued that inability to access and utilise ICT directly impacts the sense of 'belonging' to the professional team and active participation in the Community of Practice in the Clinical area. This research develops the evidence in the field by exploring the extent and modes of ICT use in practice in a group of mature, female nursing students on a pre-registration nursing programme located in a UK School of Health and related NHS Trust. The findings arise out of qualitative case study research using observation and interviews within practice to ascertain the answers to 3 questions:1) How are mature, female nursing students accessing and using ICT within nursing education? 2) What are the barriers that may prevent mature, female students from accessing and using ICT within nursing education? 3) What actions do mature, female nursing students consider may be taken to improve their knowledge and subsequent use of ICT in both their academic studies and clinical placement work? Findings indicated that biographical history, student support and facilitation all affect access and engagement, the data suggesting that for a significant group of students they felt generationally, emotionally and hierarchically 'locked out' of using ICT in clinical settings. This resulted in feeling excluded from the Community of Practice (COP). The findings raise issues around whether the UK Government policy and regulations is being successfully enacted for these students and the extent to which failure to do so contributes to a lowered sense of 'belonging' to the clinical teams This study, focused on pedagogical practice for preregistration nurse education programmes and the need to privilege and enable ICT usage in clinical situations. This study potentially challenges the perspectives of Lave and Wenger (1991) in their description of the ways in which COP emerge as participants move from the periphery to the centre; by arguing that barriers on the periphery such as being logged out of ICT, block the trajectory of movement causing potential COP participants to remain on the periphery and excluded from the COP. It emphasises the need for a collective efficacy in nurse pre-registration programmes that is suggestive of notions of being ICT 'logged in' rather than being 'locked out' for mature, female student nurses recognising that the experience of being 'locked out' may not be restricted to ICT but also to associated Communities of Practice.
\end{abstract}

Keywords: Communities of Practice, Technology, student experience, ICT

\section{INTRODUCTION}

There has been a growing expectation with the National Health Service (NHS) that practitioners would make full use of the Information and Communication Technology (ICT) available in the workplace. The UK Department of Health (DH) has recognised that continuous enhancement of ICT is essential to effective, good quality patient care. Within Nursing, technology opened up new areas of progress [1] based upon the view that electronic data and associated disseminated knowledge contribute significantly to patient care. This builds upon the understanding that ICT provides a rich, focused, data informed evidence base which underpins professional practice [2]. Johnson and Eisenberg emphasise the need for student nurses to be able to use technology in a purposeful way and that the associated ICT skills need to be part of nurse education [3]. It could be argued that the potential for use of ICT in nurse education is still underutilised [4][5][6]. Kevern and Webb [7] furthermore ascertain that these 
challenges are amplified by the diverse educational and occupational experiences of student nurses. This impacts confidence and usage [8]. This study sought to investigate the personal experiences of ICT usage with a cohort of mature female nursing students in the UK.

Ethical clearance was obtained for a study based within a contemporary university in the North of England and the associated NHS Trust where students completed the clinical placement aspects of the course. The study centred on three questions: How are mature, female nursing students accessing and using ICT within nursing education? What are the barriers that may prevent mature, female nursing students from accessing and using ICT in nurse education? And What actions do mature, female nursing students consider may be taken to improve their knowledge and subsequent use of ICT in both their academic studies and their clinical placement work?

\section{LITERATURE}

Literature around this study was based around two generic themes. These were (a) computer and information literacy in the health services and (b) nurse education and nurse informatics.

\section{a) Computer and Information Literacy in the Health Service and Nurse Education}

Computer literacy is individual's ability to interact with a computer [9]. Whereas information literacy focuses on the ability of an individual "to recognise the need for information, determine the extent of information needed, access information efficiently, critically evaluate information and its sources, classify, store, manipulate and redraft information collected or generated and incorporate selected information into their knowledge base" [10].

Bond noted the advancement of computing policies within the NHS identified that the nature of computing policies within the National Health since the initial Information for Health policy which marked a shift in ICT focus for the NHS [4] [11]. "For the first time the focus moved away from the computer and onto the patient, promoting IT as a tool that could be used to improve both patient care and patient experience" [4]. The High Quality Care for All report [2] further highlighted where the use of computers was viewed as having a major support role within differing healthcare settings [4].Bond found that student nurses were still unable to handle large amounts of data retrieved through online data base searches and she further advised that pre-registration nursing curricula within the United Kingdom did not prepare students to work with ICT in the way that expected of the graduate registered nurses[4]. Magg concluded that formal ICT education for student nurses within pre-registration nursing curricula was limited and consideration should be given to the formulation of an entry level technology skills test which should be used to determine a student's ICT competence on their admission to the pre-registration nursing course [12]. Creedy argued that there is a consistent lack of computer literacy amongst undergraduate student nurses especially in relation to search skills and not all students are computer literate at the commencement of their pre-registration nursing studies [13]. Creedy considered that the students' biographical profile on admission to the university might be a factor in relation to literacy [13]. It was suggested that these students needed time and support in order to gain the necessary confidence to master and use ICT in a meaningful way [14]. Washer identified that there was still some reticence amongst female student nurses towards computer and Internet use [15].

Some older adults have not grown up with mobile phones, computers and "other currently popular devices and are more likely to use the Web for online shopping and banking coupled with engagement with social media. Scott found that undergraduate student nurses possessed inadequate information literacy skills even though their actual computer skills may have been more advanced [16]. Low levels of information literacy amongst both student and qualified nurses may eventually lead to inadequacies in the ways that patients' nursing care needs are assessed, planned, implemented and subsequently evaluated. In addition, While and Dewsbury argued that ICT would bring benefits to patients but place greater demands upon the skills of nurses [17].

'Information literacy' exists within the Nursing and Midwifery Council as a competence but is still to be fully understood within the context of clinical nursing care. Nayda and Rankin suggested that there was a low level of understanding as to what exactly 'information literacy' meant to both groups and therefore nurse educators particularly should not presume any level of information literacy in student nurses at the commencement of their course [18]. 


\section{b) Nurse Education and Nurse Informatics (NI)}

Nurse informatics is the set of ICT skills required by the registered nurse in carrying out their nursing duties. The term encapsulates the necessity to integrate nursing science, computer science and information science in order to manage and communicate data, information and knowledge in nursing practice [19]. There is an imperative for all practicing nurses working in healthcare settings to develop and improve their ICT skills in order to maximize the potential of technological developments. Accessing patient diagnostic information and evidence/research bases enables the provision of the best holistic patient care [20].

McMahon et al explored the barriers to ICT experienced by students and concluded that situational factors (e.g. access, training and time) influence computer usage although it did not consider the cumulative impact of these variables [21]. Moule argued that female students on an undergraduate nursing programme experienced some initial anxiety when first using a computer, a feeling that continued whenever they were faced with a new or unfamiliar technology experience and this was further marked amongst the more mature, female students [22]. Russell and Alpay supported a connection between situational factors and ICT use citing inadequate or non-existent ICT training for nurses [23]. Faced with educators who remained unaware of their learning needs in relation to ICT impacted not only ICT use but also the response to formal ICT training. This resulted in negative associations with ICT and feelings of discomfort. Concerns also exist over the divide which can be created between the ICT proficient and those who lack these skills [24].

Moule considered that in order to increase the level of nursing informatics within pre-registration curricula it would require not only nurse educator training but also both financial and perhaps more importantly, technical support [22]. It can be argued that a lack of ICT and informatics support affects the expertise that students need and when they become mentors they are unable to support the development skills of the next generation of learners, thereby creating a vicious circle [4].

Most of the studies in these areas are descriptive and lack the engagement with how to rectify the issue and understand fully how ICT usage in nurse education programmes are experienced, understood and enacted. In addition, there appears to be little theoretical discussion as to what factors structure and determine the agency of mature, female nursing students in the context of their programmes. Meanwhile the student 'voice' can be potentially unheard in this context and therefore the impact on lived experience can be overlooked.

\section{METHODOLOGY}

Utilising a qualitative, case study approach this study examined the biographical, university and clinical placement use of ICT for the identified group of student nurses. The sample consisted of a total of sixteen student nurses (all self-selecting) across all three years of one undergraduate preregistration nursing programme. Twelve of these were interviewed across four separate focus groups and four were interviewed individually. All female, student nurses of twenty-six years of age or over from this undergraduate pre-registration nursing programme were eligible to take part. Addressing the research question required an in-depth understanding of how and why mature, female student nurses used ICT. This included understanding how clinical placements impacted on the possibilities of ICT usage. This was achieved through direct (non-participant) observation. Observation formed part of the academic and educational audit role as a Clinical Link Lecturer in the clinical setting. Notes taken from both educational audits and observations provided additional data to supplement that obtained from the focus groups and individual interviews, which enriched and helped to triangulate the collected data. All interviews were digitally recorded and then transcribed verbatim. All transcriptions were accompanied by personal notes made during and following completion of the interviews. These notes provided salient points to readdress and 'come back to' with the participants during the interview process. Savin-Baden and Howell Major assert that data analysis within the realms of qualitative research is an on-going process of breaking down of data into meaningful parts for the purpose of 'making sense out of that data'[25]. The data is then reassembled to make sense. A thematic approach was adopted as Boyatzis suggests that "thematic analysis is a way of 'seeing' [26]. Such analysis traverses three phases of inquiry: recognising importance (seeing), encoding (seeing it as something) and interpretation. As part of this process transcripts were read several times to identify key themes [27]. Generation of codes enabled an analytical approach to organise date and list initial ideas and then determine repeated patterns. Braun and Clarke argue thematic analysis has some 
disadvantages in that: "thematic analysis has limited interpretative power beyond mere description if it is not used within an existing theoretical framework that anchors the analytic claims that are made" [28].

\section{RESULTS}

One of the findings was that students entered the programme with varying personal backgrounds, different levels of confidence and different ICT experience. A continuum existed form confidence and others who had very limited exposure to ICT.

“... when I was at school (ITC) just wasn't available. We certainly didn't have Internet access at home until I was about eighteen or something and even then, it was rare if you had it. In the last ten or fifteen years it has become more available. So, I'm self-taught but l've learned a few tricks obviously supporting kids in schools. They know more than me!" (Linda (45yrs)

Some students described ICT use in particular ways, such as online shopping, banking, social networking, email and electronic games.

"Well just logging on and emailing and just general things like that, emailing friends. I hadn't used word before, so I had no idea how to use a computer that way" Norma (46yrs)

"Games and that was it. I just used to play games. I could turn it on and off. If it didn't work, it got left". (Focus Group 3; Jane (31 yrs.)

Attending university increased computer use:

"I've only started using my laptop since I started here. Because I never needed to use it before I just used it really for Internet shopping when it came up to Christmas (laughter), but I've never used it, I've never had to use one..." (Susan (48years)

Even where students had undertaken an ICT course they still felt unskilled and underconfident.

"I've done the one that was previous to the European Driving Licence.........CLAIT yes, I've done CLAIT and I've done all of those and I'm fine on that side of it but what I'm not good at is I just don't understand them, and I find it very difficult." (Olivia (34years)

For some, ICT courses proved more beneficial and helped to remove barriers to ICT use on the course:

'But when I had children as they went to school we thought we should get an up-to-date computer, so I actually went to college and did the RSA CLAIT, which is like a programme for using in offices, word processing and things like that, so I updated a bit there. Then l've just picked the IT skills up. All along l've been using computers at work to do my work, office based, so I have no phobia about them or anything because l've had the keyboard skills there all the time." (Martha (42years of age): 81-90)

Students described areas of ICT learning including using Virtual Learning Environments, WebCT and Blackboard as well as PowerPoint in addition to using ICT in clinical settings. Personal experience and background influences ability to use technology. Students described varied opportunities to learn about computing, but with different levels of success.

"We had a module in the first year. I didn't find it very useful though because I didn't think that it taught me anything I didn't already know about computers" (Jane (31 years of age)

'I always knew how to use computers, but I wouldn't say that I have been taught anything in my first year on how to use them...' (Harriet, 28yrs)

".......we had a couple of lessons on guidance and using e-learning and using Word really and how to do it and we had a lesson on using Discovery so that we could find the journals and using the library, using on-line library resources, and how to book books in the library to go and pick up. So that was all new to me......" (Brenda (52years)

Use of ICT within clinical area was very variable and this did not seem to depend on clinical speciality:

"It's limited because we are not allowed direct access unsupervised. We are not allowed passwords, but we are allowed to go on and do the assessment sheet, the triage sheet. Everything has to be supervised really." (Linda (45yrs) 
"...but we are allowed in the Intranet, so we can use the Intranet whenever we like, not password protected, to look at the policies and procedures and look at the news from different areas. We are just not allowed to access patient files or any confidential things." (Linda (45yrs of age)

Students were not always actively encouraged to use computers on the wards:

"Not when you are a student. It is really strange......... you get results and you get your patients' names, beds, where they are...... it makes me feel a bit useless to be honest. You can get a sample of urine and it could be sat there for four hours because you have to rely on someone else. Yes, you can handwrite it and l've had to do that...In my first year at.........they showed me how to do it all but yet here I am in my third year and l've not been shown how to it." Julia (28 years)

In summary the data suggests that students had limited access to ICT focused on NHS intranet searching. Patient data access appeared to be mainly available only to those employed by the Trust.

In terms of barriers to accessing ICT, students described being 'locked out' generationally, emotionally and situationally and hierarchically. The first of these related to mature students feeling a generation gap

"I feel like my grandma must have felt when decimal currency first came in I think. Because we were young, and you were brought up to use it you didn't know any different but poor grandma struggled and we found it difficult to comprehend why she struggled". (Susan (48years of age)

This generation gap was pivotal to how these students associated age with ICT ability, difficulties which could lead to students withdrawing from the programme.

"I think on a couple of occasions it's even led to some dropping off the course. You know of students, I mean not loads and l've not got that much experience yet with this new curriculum, but students that don't submit and when you get to the bottom of it it's actually because they've not worked out how to use the e-learn, where to get the assignment guidelines from, how to get in their e-portfolio, and that's led to them dropping out I think." (Lecturer; Francis)

Penny described how overwhelming the language used in ICT instruction could be for students:

"It's like a new language isn't it, I think it's... You know you get women in their thirties and forties, who've been doing their caring profession for so many years, but they just can't use a computer, so I think you would have got quite a few that's dropped out because of that reason and they could have made really good nurses....... Some people are proud as, well, aren't they? They are too proud to admit - I can't do that. What's basic to some people is overwhelming for them." (Penny (28years)

There was evidence to suggest that those who had not 'grown up' with ICT could feel excluded from ICT usage resulted in frustration and lack of confidence.

Being emotionally 'locked out' included the use of emotive language to describe their struggles with computing

"I've got children and they are obviously a bit older because with my age and my children tell me what to do when I get stuck. Also, because having to use it at Uni I just dread it. I sit there, and I send things off and I don't believe it's ever gone and I have had training in how to do it and I still don't really understand anything." (Olivia (34years)

Susan, describes in detail the stressful conversations started at home with her son, Brian;

"I got really upset and I panicked. I said - I don't even know how to use my laptop. All I got from Brian was - well I have been telling you mother, I have been telling you for the last few months you should be practicing on it, blah, blah, blah. I said to him - but Brian you know, and he said - no never mind, l've shown you stuff, and instead of practicing it every night mum you've left it and now you come back to me a fortnight later and say Brian how do I do this. He said, which I thought was a bit hard - you're wasting my time mum and you're wasting your own. I got right upset then and I ended up in tears to be honest..." (Susan, 48yrs)

Her confidence centred on understanding the terminology used within lectures and this caused additional confusion, fear and a feeling of inadequacy. 
Jane also reflected on her feelings about using ICT stating that,

"I was terrified, absolutely terrified. If I hadn't done the Open University course I think I would have been in pieces. But I was scared. I did a year of my training a long time ago and it was all on paper and I knew about essays, but it was such a change." (Focus Group 3; Jane (31 years of age): 182183)

"I'm frightened to death of losing something. My husband and my son who use them all the time say - you can't lose anything, you can't lose anything. But if you can't lose anything why do people sometimes go - oh l've lost all my work!" (Susan (48years of age)

The online submission of assignments was also seen as stressful and indicates the degree of anxiety.

"I mean if we had been shown how to do it maybe it wouldn't have been so stressful." (Focus Group 3; Georgina (26years)

Being 'situationally and hierarchically locked out' stems from the more limited access to ICT that the students encountered, particularly in clinical placements. All students irrespective of age were found to be in the same situation. Jane perhaps best exemplifies some of the frustration experienced by being 'locked out' from ICT usage on placement

"Yes, sometimes it can be a little bit frustrating when you can see how busy everybody is and you think - I could help. I could carry on and finish that instead of having to stop somebody and say please put this in the computer for me. That is frustrating sometimes because you feel you are taking them away from their other jobs to do something you've started." (Jane (31 years)

In some NHS Trusts the students were not given personal passwords to access the ICT systems and were therefore unable to access patient documentation electronically. This led to situations where students were required to ask other members of the ward team to access the information for them.

'.... you are going so far and then you've to stop and that can be frustrating because I do think it's easier the more information you have. I can understand maybe as well why we can't have all the information." (Jane (31 years)

Confidentiality was cited as an issue, but students pointed out that they already had access to this information from admission or from verbal discussions with the patients and therefore felt that this was not an acceptable explanation. Sometimes it was possible to request a student password from the Trust ICT Department, but this was very 'hit and miss' and on several occasions students had reached the end of their allotted period of time on the particular clinical placement still not having been issued with an access code; this rendered some of their work invisible as explained by the clinical mentors.

Mentors acknowledge that this excluded students from feeling part of the team and that this was not fair; on occasion they were also physically locked out of spaces because they didn't have a swipe card. "You are asking a student to feel part of a team and then you are asking them to go off and they've got learning objectives to complete and be assessed on but they've not got the full tools to be able to do it. It doesn't seem fair really does it?" (Mentor; Beatrice)

"I was isolated outside the changing rooms a lot of the time (laughing). I had to knock on the door and wait for someone to answer or ... another member of staff to let me in....I felt a bit embarrassed right at the beginning, like the first week I was stood outside waiting, but I got used to it, it never bothered me towards the end...they (the staff) just used to laugh and say - l'll let you in." (Stephanie (26years)

Being 'locked out' is important as generation, hierarchy and emotion are all areas which act as barriers to engagement with ICT, but more than that, they act as barriers to belonging to the team. Students can regard themselves as 'older' and less able leading to feelings of inadequacy and fear. From a situational and hierarchical perspective, the concept of 'being locked out' was demonstrated more broadly through the lack of provision of personal passwords in order to access not only electronic patient records but also other more basic, yet important, resources within the NHS Trusts like the changing rooms. This led to feelings of isolation, a sense of being 'only the student' and therefore not a real part of the ward team. Brenda concludes;

“...... it makes you not value yourself as much I suppose because they don't. Although I've always had good feedback from the placements and they've said l've worked well and things. In a way it makes you take a back seat sometimes depending, not on every placement but sometimes it can make you take a back seat. Because you think - oh I don't want to get in the way and I'm not allowed 
to do that. If you were allowed to get on more, you would probably appear a bit more forthcoming in everything." (Brenda (52years)

\section{CONCLUSIONS}

\section{Communities of practice and belonging}

The importance of a support of mentor is recognised as important in relation to the development of professional identity and management of stress, [29]. Positive, supportive learning environments which place students at the centre can assist in nurturing professional socialisation [30]. Wenger's development of his ideas around communities of practice (CoPs) [31] provides a useful cognitive model of situational learning which relates to this context. CoPs are a type of learning community in which individuals are motivated to join in order to gain a sense of belonging and professional identity [32]. This is compounded by Field who asserts: "a growing body of educational thought has emphasised the socially and culturally situated culture of knowledge and particularly the role that activity and experience play in learning practical skills" [33] CoPs provide a framework which enables collaborative learning. "They are situational, rooted in practice and allow for the mixing of novices with experts, academics with practitioners and mentors with the mentored" [34].

Such communities are rooted in collaborative relationships between peers. The participants are recognised as having a common purpose and shared interests which are based on not only task completion but also on acquiring knowledge [31]. Within nursing practice and education, the development of CoPs helps to foster the belonging, participation and collaboration which are considered so important and fundamental to the development of practitioners and the sustainability of the COP [34]. Berry argues that students may feel disconnected and that one of the underlying reasons for this focused on the dissonance between nursing education and nursing practice. It could be argued that this dissonance exists at a systematic level [35]. Berry continues:

"Creating learning communities where students are integrated into the learning fabric of the clinical setting necessitates a reconceptualization of the relationship between nursing service and education. This reconceptualization envisions the creation of environments where mutual learning and growth are the key goals for both students and clinicians. Such mutually beneficial, capacity building relationships between education and practice will ultimately improve the quality of patient care."

Therefore, COPs can minimize the effects of alienation and marginalisation experienced by student nurses in clinical practice. Within the study there was evidence that although support was provided during clinical placement there were also many areas where students felt that they were peripheral to the community and the group. Hierarchical policies and protocols were responsible for 'locking out' students in an environment where they were unable to have control or had only limited control. This in turn proved to be a boundary to being part of an aspirational community of practice, effectively rendering them 'locked out.' This resonated with the main research question of the study and the concept of being 'locked out', this is an important concept in relation to their lived experience. This provided insights into the barriers which exist for mature female student nurses and their ability to access ICT systems in the clinical area and gain the skills in the university setting. Some of this was linked to generational experiences, the barriers often relation to life experience and the opportunity to gain and practice ICT skills. Students often compared themselves with the younger students in their cohort who they perceived as having little difficulty with these issues. The 'generation gap' acted as a psychological barrier to their learning. Although younger peers also reported degrees of frustration with accessing ICT, so this was not entirely the preserve of older students. However, the mature students articulated feelings of inadequacy, intimidation, embarrassment and fear.

Emotional 'lock -out' was significantly linked to individual student biographies and self-efficacy. Data demonstrated that the more, mature students experienced the greater degree of computer anxiety which consequently resulted in acting as a barrier to ICT usage. These feelings had proved to be overwhelming for some students, ultimately leading to the withdrawal of these students from the preregistration nursing programme altogether. For others though the understanding of the key significance of developing ICT skills in order to fulfil their role had underpinned a strong commitment to develop and continuously improve their ICT skills. Therefore, it is important to note that all students 
experienced a sense of being 'locked out' in a situational and hierarchical sense, not having access to ICT, but for some there was also a perceived generational overlay which exacerbated this.

Hierarchical relationships, the tendency towards compliance and conformity within the culture of the NHS acted as barriers to accessing and utilising ICT in clinical areas. This inability to fully participate in this area without difficulty contributed to difficulties in the development of a professional identity. Students lacked the means to contribute to and undertake some nursing activities and this proved to be a source of embarrassment and a factor which led to isolation within the team. The lack of 'belonging' to a CoP, access to which was beyond their control was a factor in feeling 'locked out' and peripheral to the community. Furthermore, this experience 'locked them in' to an excluded culture of isolation which they found disempowering.

Lave and Wenger, and more latterly Wenger, have further developed theories concerning CoP's [31] [36]. The data from this study suggests that such CoP do not appear to pertain to student nurses' ICT clinical work. Lave and Wenger advocate a theory that relates to the importance of both social and cultural dimensions within CoPs [31]. They describe a relationship between master and apprentice where the inexperienced learn from the experienced and this constitutes an environment where individuals joining the community start at the periphery and move over time towards the centre. In the present context movement is limited, and students remain clearly at the periphery of the CoP. This, it could be argued, appears to refute Lave and Wenger's work on the master/apprentice relationship with regard to student nurse experiences and the perceived CoPs in which they work.

In educational terms there is a dissonance between theory and practice. It is interesting to explore why this dissonance exists and why it persists in this context. HEls need to consider the lived experience of student nurses in clinical practice and seek measures which rectify this element of exclusion during placement.

\section{ACKNOWLEDGEMENTS}

The authors wish to thank the students, lecturers and mentors who participated in this research.

\section{REFERENCES}

[1] Lowry, M \& Johnson, J. (1999) Computer Assisted Learning: the potential for teaching and assessing in nursing. Nurse Education Today. 19, pp. 521-526.

[2] Darzi. (2008) High Quality Care for All: NHS Next Stage Review Final Report. London. The Stationery Office.

[3] Johnson, D. \& Eisenberg, M. (1996) Computer Literacy and Information Literacy: a natural combination. Emergency Librarian. 23 (5), pp 12-23.

[4] Bond, C. S. (2009) Nurses, computers and pre-registration education. Nurse Education Today. 29, pp. 731-734.

[5] Mavrou, K. (2011) Assistive Technology as an emerging policy and practice: Process, challenges and future directions. Technology and Disability. 23, pp. 41-52.

[6] Francis, R. (2013) The Mid Staffordshire NHS Foundation Trust Inquiry. London. The Stationery Office.

[7] Kevern, J. \& Webb, C. (2004) Mature women's experiences of pre-registration nurse education. Journal of Advanced Nursing. 45(3), pp. 297-306

[8] Wilkinson, A., Roberts, J. \& While, A. (2013) Nursing students' use of technology enhanced learning: A longitudinal study. Journal of Nursing Education and Practice. 3 (5), pp. 102-115.

[9] Poynton, T.A. (2005) Computer literacy across the lifespan: a review with implications for educators. Computers in Human Behaviour. 21, pp. 861-872.

[10] Bundy, A. (2004) cited by Button, D., Harrington, A. \& Belan, I. (2014) E-learning \& information communication technology (ICT) in nursing education: A review of the literature. Nurse Education Today. 34 (10), pp. 1311-1323. 
[11] NHS Executive (1998) Information for Health: An Information Strategy for the Modern NHS 1998-2005. London. NHS Executive

[12] Magg, M. (2006) Nursing Students Attitudes Towards Technology. Nurse Educator. 31 (3), pp. 112-118.

[13] Creedy, D.K, Mitchell, M., Seaton-Sykes, P., Cooke, M., Patterson, E., Purcell, C. \& Weeks, P. (2007) Evaluating a Web-Enhanced bachelor of Nursing Curriculum: Perspectives of Third-Year Students. Journal of Nursing Education.46 (10), pp. 460467.

[14] Kozlowski, D. (2002) Using online learning in a traditional face- to- face environment. Computers in Nursing. 20, pp. 23-30

[15] Washer, P. (2001) Barriers to the use of web-based learning in nurse education. Nurse Education Today. 21, pp. 455-460.

[16] Scott, S.D. (2008) 'New professionalism' - shifting relationships between nursing education and nursing practice. Nurse Education Today. 28 (2), pp. 240-245.

[17] While, A. \& Dewsbury, G. (2011) Nursing and information and communication technology (ICT); A discussion of trends and future directions. International Journal of Nursing Studies. 48, pp. 1302-1310.

[18] Nayda, R. \& Rankin, E. (2009) Information literacy skill development and lifelong learning; exploring nursing students' and academics' understandings online. Australian Journal of Advanced Nursing. 26 (2), pp. 27-33

[19] Button, D., Harrington, A. \& Belan, I. (2014) E-learning \& information communication technology (ICT) in nursing education: A review of the literature. Nurse Education Today. 34 (10), pp. 13111323.

[20] Wharrad, H.J, Cook, E, \& Poussa, C (2005) Putting Post-Registration Nursing Students on-line: Important Lessons Learned. Nurse Education Today. 25, pp. 263271.

[21] McMahon, J., Gardener, J., Gray, C. \& Mulhern, G. (1999) Barriers to student computer usage: staff and student perceptions. Journal of Computer Assisted Learning. 15, pp. 302-311.

[22] Moule, P (2003) ICT: a social justice approach to exploring user issues? Nurse Education Today. (23), pp. 530-536.

[23] Russell, A. \& Alpay, L. (2000) Practice Nurses' training in information technology: report on an empirical investigation. Health Informatics Journal. (6), pp. 142-146

[24] Reime, M.H., Harris, A., Aksnes, J. \& Mikkelsen, J. (2008) The most successful method in teaching nursing students infection control - E-learning or lecture? Nurse Education Today. 28 , pp. 798-806.A.A. Author, "Journal/Conference Article Title," Periodical Title, vol. Volume, no. Issue, pp.-pp., Publication Year.

[25] Savin-Baden, M \& Howell Major, C. (2013) Qualitative research. The essential guide to theory and practice. London. Routledge.

[26] Boyatzis, R.E. (1998) Transforming Qualitative Information: thematic analysis and code development. London. Sage.

[27] Teddlie, C. \& Tashakkori, A. (2009) Foundations of Mixed Methods Research. Integrating Quantitative and Qualitative Approaches in the Social and Behavioural Sciences. London. Sage.

[28] Braun, V. \& Clarke, V. (2006) Using thematic analysis in psychology. Qualitative Research in Psychology. 3, pp. 77-101.

[29] Levett-Jones, T., Kenny, R., Van der Riet, P., Hazelton, M., Kable, A., Bourgeois, S. \& Luxford, Y. (2009) Exploring the information and communication technology competence and confidence of nursing students and their perception of its relevance to clinical practice. Nurse Education Today. 29, pp. 612-616.

[30] Prato, D.D., Bankert, E., Grust, P. \& Joseph, J. (2011) Transforming nursing education: a review of stressors and strategies that support students' professional socialization. Advances in Medical Education and Practice. 2, pp.109-116. 
[31] Wenger, E. (1998) Communities of Practice. Learning, Meaning and Identity. Cambridge. Cambridge University Press.

[32] Li, L.C., Grimshaw, J.M., Nielson, C., Judd, M., Coyte, P.C. \& Graham, I.D. (2009) Evolution of Wenger's concept of community practice. Implementation Science. 4: (11), pp. 1-8.

[33] Andrew, N., Tolson, D., Ferguson, D. (2008) Building on Wenger: Communities of practice in nursing. Nurse Education Today. 28, pp. 246-252.

[34] Field, D (2004) Moving from novice to expert- the value of learning in clinical practice: a literature review. Nurse Education Today. 24, pp. 560-565.

[35] Berry, L.E. (2011) Creating Community: Strengthening Education and Practice Partnerships through Communities of Practice. International Journal of Nursing and Scholarship. 8 (1), pp.118

[36] Wenger, E. (2008) Communities of Practice. Learning, Meaning and Identity. Cambridge. Cambridge University Press. 